\title{
Direct fabrication of bio-inspired gecko-like geometries with vat polymerization additive manufacturing method
}

\author{
Davoudinejad, A.; M. Ribo, M.; Pedersen, D. B.; Islam, A.; Tosello, G.
}

Published in:

Journal of Micromechanics and Microengineering

Link to article, DOI:

10.1088/1361-6439/aabf17

Publication date:

2018

Document Version

Peer reviewed version

Link back to DTU Orbit

Citation (APA):

Davoudinejad, A., M. Ribo, M., Pedersen, D. B., Islam, A., \& Tosello, G. (2018). Direct fabrication of bio-inspired gecko-like geometries with vat polymerization additive manufacturing method. Journal of Micromechanics and Microengineering, 28, [085009]. https://doi.org/10.1088/1361-6439/aabf17

\section{General rights}

Copyright and moral rights for the publications made accessible in the public portal are retained by the authors and/or other copyright owners and it is a condition of accessing publications that users recognise and abide by the legal requirements associated with these rights.

- Users may download and print one copy of any publication from the public portal for the purpose of private study or research.

- You may not further distribute the material or use it for any profit-making activity or commercial gain

- You may freely distribute the URL identifying the publication in the public portal 
ACCEPTED MANUSCRIPT

\section{Direct fabrication of bio-inspired gecko-like geometries with vat polymerization additive manufacturing method}

To cite this article before publication: Ali Davoudinejad et al $2018 \mathrm{~J}$. Micromech. Microeng. in press https://doi.org/10.1088/1361-6439/aabf17

\section{Manuscript version: Accepted Manuscript}

Accepted Manuscript is "the version of the article accepted for publication including all changes made as a result of the peer review process, and which may also include the addition to the article by IOP Publishing of a header, an article ID, a cover sheet and/or an 'Accepted

Manuscript' watermark, but excluding any other editing, typesetting or other changes made by IOP Publishing and/or its licensors"

This Accepted Manuscript is @ 2018 IOP Publishing Ltd.

During the embargo period (the 12 month period from the publication of the Version of Record of this article), the Accepted Manuscript is fully protected by copyright and cannot be reused or reposted elsewhere.

As the Version of Record of this article is going to be / has been published on a subscription basis, this Accepted Manuscript is available for reuse under a CC BY-NC-ND 3.0 licence after the 12 month embargo period.

After the embargo period, everyone is permitted to use copy and redistribute this article for non-commercial purposes only, provided that they adhere to all the terms of the licence https://creativecommons.org/licences/by-nc-nd/3.0

Although reasonable endeavours have been taken to obtain all necessary permissions from third parties to include their copyrighted content within this article, their full citation and copyright line may not be present in this Accepted Manuscript version. Before using any content from this article, please refer to the Version of Record on IOPscience once published for full citation and copyright details, as permissions will likely be required. All third party content is fully copyright protected, unless specifically stated otherwise in the figure caption in the Version of Record.

View the article online for updates and enhancements. 


\title{
Direct fabrication of bio-inspired gecko-like geometries with vat polymerization additive manufacturing method
}

\author{
A. Davoudinejad ${ }^{1}$, M. M. Ribo ${ }^{1}$, D. B. Pedersen ${ }^{1}$, A. Islam ${ }^{1,2}$, G. Tosello ${ }^{1}$ \\ ${ }^{1}$ Department of Mechanical Engineering, Technical Univ. of Denmark, Building 427A, Produktionstorvet, 2800 Kgs. Lyngby, Denmark \\ ${ }^{2}$ Centre for Acoustic-Mechanical Micro Systems (CAMM), Technical Univ. of Denmark, Building 352, Ørsteds Plads, DK-2800 Kgs. Lyngby, \\ Denmark \\ alidav@mek.dtu.dk

\section{Abstract}

Functional surfaces have proven their potential to solve many engineering problems, attracting great interest among the scientific community. Bio-inspired multi-hierarchical micro-structures grant the surfaces with new properties, such as hydrophobicity, adhesion, unique optical properties and so on. The geometry and fabrication of these surfaces are still under research. In this study, the feasibility of using direct fabrication of microscale features by Additive Manufacturing (AM) processes was investigated. The investigation was carried out using a specifically designed vat photopolymerization AM machine-tool suitable for precision manufacturing at the micro dimensional scale which has previously been developed, built and validated at the Technical University of Denmark. It was shown that it was possible to replicate a simplified surface inspired by the Tokay gecko, the geometry was previously designed and replicated by a complex multi-step micromanufacturing method extracted from the literature and used as benchmark. Ultimately, the smallest printed features were analyzed by conducting a sensitivity analysis to obtain the righteous parameters in terms of layer thickness and exposure time. Moreover, two more intricate designs were fabricated with the same parameters to assess the surfaces functionality by its wettability. The surface with increased density and decreased feature size showed a water contact angle (CA) of $124^{\circ} \pm 0.10^{\circ}$, agreeing with the Cassie-Baxter model. These results indicate the possibility of using precision AM for a rapid, easy and reliable fabrication method for functional surfaces.

Keywords: Additive Manufacturing, Functional surfaces, Biological features, Micro manufacturing, Polymer components, Biomimetics

\section{Introduction}

Biological organisms have been a source of inspiration to the scientific community due to its outstanding capabilities to survive and to adapt to the environment [1], [2]. Most of the talents found in nature e.g. the superhydrophobicity of the lotus leaf or the dry adhesion found in gecko toes, are traced to be due to the nano-and microstructures of surfaces acting as an interface between environment and specimen [3]. This type of features is used in wall climbing robots[4], grippers for other robotics applications [5], hydrophobic shells for hearing aid etc. These so-called functional surfaces are often artificially manufactured by virtue of nanotechnology to create technologically advanced products [6] (e.g. water repellent textiles inspired by the lotus leaf [7], dry adhesive textile and tape with gecko toe pad mechanism as inspiration [8]). Although successfully manufactured, these products can be prohibitively expensive to produce and far from mass production [9]. Moreover, there is still need for further understanding all the factors involved in the functionality of different surfaces (i.e. chemistry, hierarchical assembly, topography and complementary subsurface) and how they interact [10]. 
A popular example of bio inspiration is the Tokay gecko. This animal has the unique ability to cling to most of surfaces - smooth, rough, vertical or even upside down [11]. This dry adhesion is achieved through Van der Walls forces [12]. If looked closely, the toe pads are covered by a patterned 400-600 $\mu \mathrm{m}$ thickness flaps (i.e. lamellae), each of which formed by an array of hundreds of micro hairs or setae of 3-5 $\mu \mathrm{m}$ thick and 30-130 $\mu \mathrm{m}$ long, which terminates in a subdivision of 100-1000 nanoscale spatulae ( 200 nm) [10], [13], [14]. Each setae generates an average of 40$400 \mu \mathrm{N}$ adhesive force [15] (depending on the amount of spatulae per seta) with an adhesive force of $\sim 10 \mathrm{nN}$ per spatulae [14], leading to an adhesion of approximate $10 \mathrm{~N}$ per $100 \mathrm{~mm}^{2}$ of pad area [13].

Aside from adhesion, geckos are known for their versatile functionalities. Autumn et al. reported in 2002 superhydrophobicity with water contact angles in the range of $160^{\circ}$ [12]. This superhydrophobicity grants geckos with a self-cleaning mechanism, another attractive feature sought in engineering materials [16]. This wetting behaviour also presents the opposite regime where the toe pad is soaked in water, hence the surface switches to a superhydrophilic state [17]. This paradoxical phenomena of two opposite regimes with the same surface (aside from selfhealing) is found to be an important limitation when reproducing gecko surfaces. The current literature reports rather successful gecko tapes; nevertheless, their performance ultimately depends on the environmental conditions. Geckos, in turn, adapt and maintain their functions given various environments [18], [19]. The consolidation of multifunctionalities found in geckos, such as adhesive strength and hydrophobicity/self-cleaning, led researchers to scrutinize these lizards and come up with state-of-the-art manufacturing methods, to ultimately create exceptional adhesives in the near future [6].

\subsection{Scope and Aim}

Subtractive manufacturing method, such as micro milling process has been utilized for several decades due to the flexibility and efficiency of the method for fabrication of 3D micro features for different materials [20][21]. A study investigated fabrication of microfluidic devices using micro milling process. Due to the compatibility for biology applications plastic material was used as a workpiece [22]. Another study micromachined drug delivery structures with $30 \mu \mathrm{m} \times 30 \mu \mathrm{m}$ dimensions on metal or polymeric material [23]. However due to the complexity of the features this method is not very popular for the biological manufacturing method.

The most conventional strategies to fabricate hierarchical structures are photolithography, soft lithography, or a combination of both [24]-[26]. Soft-lithography based approaches are the most common, specially replica moulding (REM) [26], [27]. REM counteracts the restrictions found in photolithography [28], it is cost-effective, less time-consuming, material versatile and allows $2 \frac{1}{2} \mathrm{D}$ geometries [29], [30]. Nonetheless, in REM a master mask is needed; therefore, if a variety of geometries are reproduced, the process becomes notably arduous and laborious.

Brodoceanu et al. [24] analyzed a compilation of micromanufacturing processes for hierarchical gecko-inspired functional surfaces, highlighting the achievements by means of adhesive forces and superhydrophobicity, and challenges (e.g. fiber buckling) encountered. The core of this study was to identify polymer-based microfabrication strategies, for structural geometries (non-fiber based 
methods) and their drawbacks. Accordingly, additive manufacturing with a vat photopolymerization process [31], commonly known as Digital Light Processing (DLP) based 3D printing, it is suggested to efficiently fabricate functional surfaces. Since the focus of this study aims the feasibility of the manufacturing method, instead of an adhesion test (which requires an intricate setup), the samples validation will be executed by microscope observations and water contact angle (WCA) tests.

Table 1 summarizes some manufacturing strategies in literature [24]. The first one, Photolithography and soft lithography [32], is a conventional photolithography and soft lithography combination. The following, 3D Direct Laser Writing [33], represents a more novel approach by using two-photon polymerization (2PP), where a photoresist is polymerized locally, allowing more intricate geometries $2 \mathrm{PP}$ technique allows fabrication of prototypes with arbitrary geometries and nanoscale resolution by using proper processing parameters, 2PP can fabricate feature sizes of less than $100 \mathrm{~nm}$ and beyond the diffraction limit of light[22] [34]. Another study investigate hydrated structures of lateral linewidth down to $0.5 \mu \mathrm{m}$ with $2 \mathrm{PP}$ method and indicated to a few $\mu \mathrm{m}$ lateral and axial resolution [35]. Dip-transfer [36], is another method combines a 3D printed mould to create mushroom-shaped PU pillars, dipping them in PU and placed on an etched mould to create the second (and smaller) hairs. Some techniques were also applied for fabrication of micro features, Milionis et al. [37] investigated different manufacturing approaches to create water-repellency and functionalize the surfaces of 3-D printed heat exchangers fabricated from acrylonitrile butadiene styrene (ABS). The structures were printed linear with a commercial Fused Deposition Modeling (FDM) 3D printer with the resolution about $100 \mu \mathrm{m}$. The printed materials had the form of miniature heat exchangers with continuous and interrupted fins. The wet chemical pretreatment, followed by fluorocarbon layer deposition and a rubber coating material were employed for coating the printed parts. The significant improvement of the coatings were found to the performance of the heat exchangers in terms of increased water drainage. The superhydrophobic coatings was evaluated in different studies and reveals to reduce adhesion with low surface energy chemistry and nano/micro roughness [38].

Feng et al. [39] studied fabricating macroscopic hierarchical superhydrophobic surfaces using dual-scale Electron-Beam Lithography (EBL) on epoxy (SU8). The primary structures were fabricated in $10 \mu \mathrm{m} \times 10 \mu \mathrm{m}$ square blocks spaced $10 \mu \mathrm{m}$ apart and secondary-features with periods ranging from $200 \mathrm{~nm}$ to $500 \mathrm{~nm}$. The superhydrophobic surfaces fabricated by EBL exhibit distinctive wetting behaviors, high and low adhesion. The moulding of sub- $\mu \mathrm{m}$ structures surfaces with polymer films were studied in [40]. The process chain to realize polymer micro structures investigated for manufacturing lotus structures. Different parts were fabricated with the constant pitch of the micro-structured pattern but various diameter and the thickness of the separating walls. 
Tab. 1 Microfabrication manufacturing strategies.

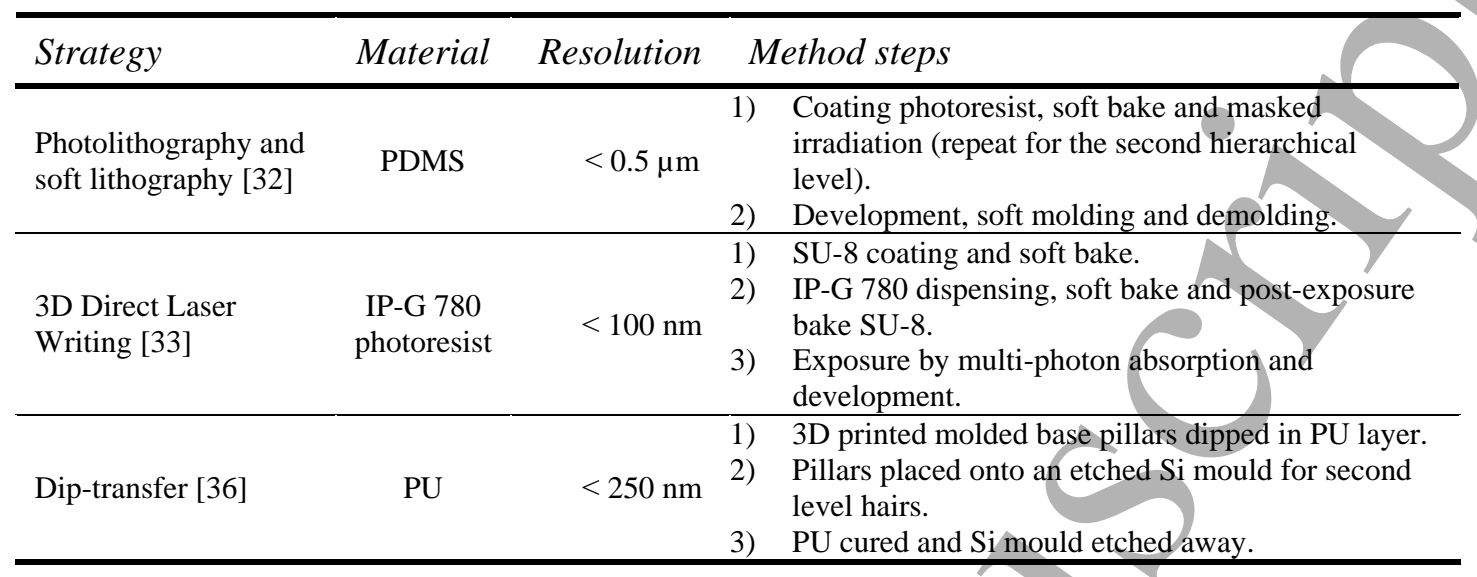

After analyzing these (among others) approaches, it was concluded that an in-depth expertise and training for these specific micro and nano manufacturing approaches is needed. Clean rooms, limited geometries, material, time and a considerable amount of investment to reproduce bioinspired surfaces can be added to the strict list of requirements and limitations [41]. Furthermore, since the working principle of the gecko toes (or other functional surfaces) are not fully understood [6], the surface designs and approaches are subjected to an iterative process which increases even more the costs of the processes. These concerns established the motivation to tackle them by using vat-polymerization as a cost-effective approach to fabricate functional surfaces, allowing the fabrication of a wider range of geometrical functional surfaces in much less time (one hour per part), and rather simple process than using an elaborated micromanufacturing process.

This study investigates the performance of a DLP AM machine for fabrication of functional surfaces with micro feature size in different geometries. In this article, firstly, the AM technology used for the experiment is defined. Afterward, the proper printing parameters setting and post processing method are selected. Then the test parts for the study are described and the measurement procedure is briefly explained. Finally the results are presented and conclusions are withdrawn.

\section{Methodology}

\subsection{AM Vat Photopolymerization Method}

The principle of vat photopolymerization is that of a liquid photopolymer resin that is contained in a shallow vat. By mask projection in the ultraviolet spectrum, geometries and features are fabricated through selective photo-initiated crosslinking of the resin [42], [43] to form solid matter, following a layered fabrication method [31], [44]. The applied method employs a DLP based video projector that contains a micro-opto-electro-mechanical mirror array, a Digital Micromirror Device (DMD), to modulate a collimated UV light source, which is subsequently focused to an imaging plane placed on the bottom surface of a transparent vat. In Fig. 1 the schematic of the process is shown. The desired geometry is built up layer by layer by modulating image masks corresponding to a sliced representation of the fabricated geometry as the vertical stage of the 
Fig. 1 Schematic representation of the DLP vat polymerization process, in a bottom-up configuration.

\subsection{Micro Vat Photopolymerization Process Chain}

Manufacturing by vat photopolymerization is a process chain that involves three main stages. The additive manufacture of part, the post-print cleaning of the part and the post-print curing of the part in order to ensure that no residual uncured resin is left on the manufactured components. The protocol for these are as follows.

\subsubsection{Additive Manufacturing}

A series of test parts to replicate the functional surface of the Tokay gecko feet were produced on an experimental photopolymerization machine-tool for precision AM. The resolution of the buildstage in the vertical direction is $0.4 \mu \mathrm{m}$. The projection mask pixel spacing is $7.6 \mu \mathrm{m}$ in the image plane, which dictate that any feature will be resolved to a $7.6 \mu \mathrm{m}$ pixel grid in the image plane and with a height corresponding to the layer height of the machine. The experimental machine-tool has been engineered, built and validated at the AM Laboratory of the Technical University of Denmark [45] as can be seen in Fig.2. The light engine of the machine tool is based on a LUXBEAM RS WQ WQXGA projector and equipped Projection Lens LRS-10 P/N 6501980 with $\mathrm{x} 1$ magnification [47]. This projector has a DMD with a $2560 \times 1600 \mathrm{px}$ array and an image plane size $20.736 \times 11.664 \mathrm{~mm}(7.56 \mu \mathrm{m}$ pitch $)$. The vertical stage of the machine tool are based upon GTen spindles with zero backlash couplings and an error of $\mathrm{e}_{300}= \pm 8 \mu \mathrm{m}$. The machine employs ISEL LFS-12-10 precision steel shaft guide rails with pillow blocks and the vertical stage assembly is resolved into $0.4 \mu \mathrm{m}$ increments at the encoded positioning accuracy limit. The repeatability of the AM process is critical in order to fabricate micro features with constant manufacturing quality, thus finding optimal parameters are imperative for a stable process. The photopolymer used for the manufacture is a proprietary methacrylate and acrylamide monomer/oligomer blend, photo initiated by a titanium dioxide based photoinitiator. 
Based on prior experiments [48], carried out for characterization of micro parts produced by AM processes by using the same AM method, a simple $2^{2}$ full factorial design of experiment DOE was carried out. The effects of the layer thickness and exposure time on the final quality were investigated. The selected exposure time was applied for each single layer during printing. Table 2 shows the experimental conditions for each level (D1 refers to the first design as shown in Fig.3 (b)). The light intensity used during experiments equates to a radiant flux of $1.75 \mathrm{~mW}$ distributed over the imaging plane.

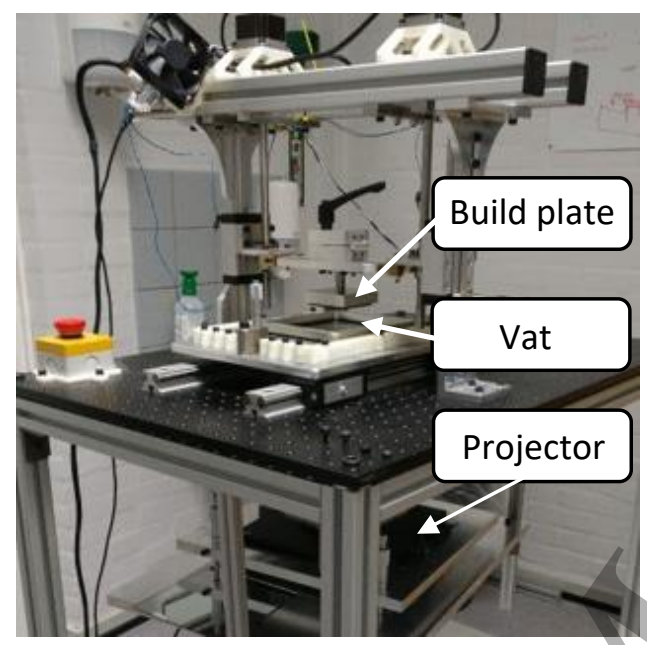

(a)

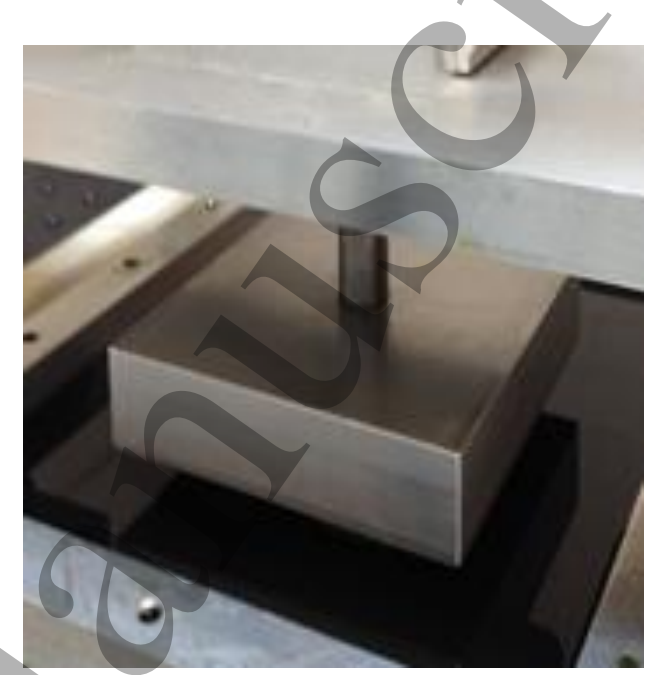

(b)

Fig. 2 (a) Experimental set-up DLP 3D printer and (b) build plate close-up.

Tab. 2 Experimental conditions of D1.

\begin{tabular}{lccc}
\hline Parameters & & Level 1 & Level 2 \\
\hline Layer thickness & $\mu \mathrm{m}$ & 15 & 18 \\
\hline Exposure time & $\mathrm{s}$ & 3.5 & 4 \\
\hline
\end{tabular}

\subsubsection{Post-processing}

The post-processing of the manufactured features consists of two steps (1) cleaning and (2) postcuring. The printed sample is carefully released from the build plate, still covered with liquid resin. To remove the excess resin from the sample, isopropanol was used for cleaning, followed by an ultrasonic cleaning ( 8 minutes cycle). Afterwards, the samples were air-dried by a controlled air jet of pressurized air flow over the micro-features, removing any remaining resin, particles and solvent residues. Finally, the parts are cured in a flood-light based post curing unit for 30 minutes with a diffuse UV light with an irradiant flux density of $300 \mathrm{~W} / \mathrm{m}^{2}$. This ensures that no reactive resin residue is left on the samples, and optimal mechanical properties are achieved.

\section{Sample designs and measurements}

\subsection{Gecko-inspired surface design}


The Tokay gecko-inspired surfaces were designed in three morphologies, mimicking the multiscale features seen on the lamella of the gecko's feet. In this study, the first design (D1) was extracted from the work of Murphy et al. [36], using the same dimensions reported in this work. The goal was to achieve the same geometrical shape and magnitude, using a simpler approach. Fig.3 (a) details the top and side views, containing mushroom shaped hairs (smallest features), each with a top diameter of $110 \mu \mathrm{m}$ and neck of $50 \mu \mathrm{m}$. The hairs are spaced $160 \mu \mathrm{m}$ apart in center to center distance. Nine hairs were placed on a bigger mushroom shaped pillars, forming and array of pillars covering an area of $18 \mathrm{~mm} \times 12 \mathrm{~mm}$. Once D1 was successfully manufactured, two new surfaces were designed (D2 and D3), conceived from the foot of the Tokay gecko in addition to be designed to be more complex-shaped as it is manufactured through AM process. (Fig.3 (c) and (d)).

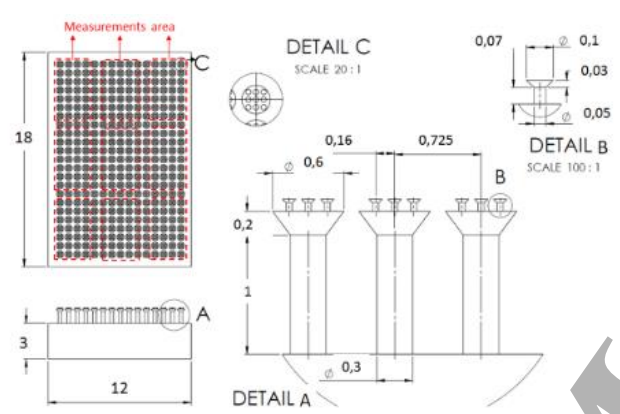

(a)

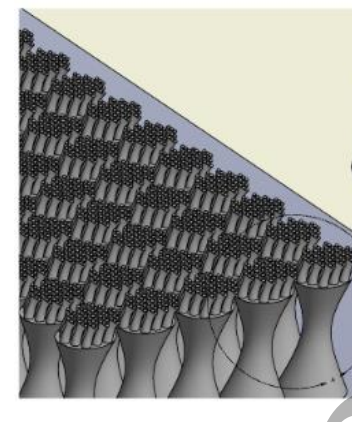

(c)

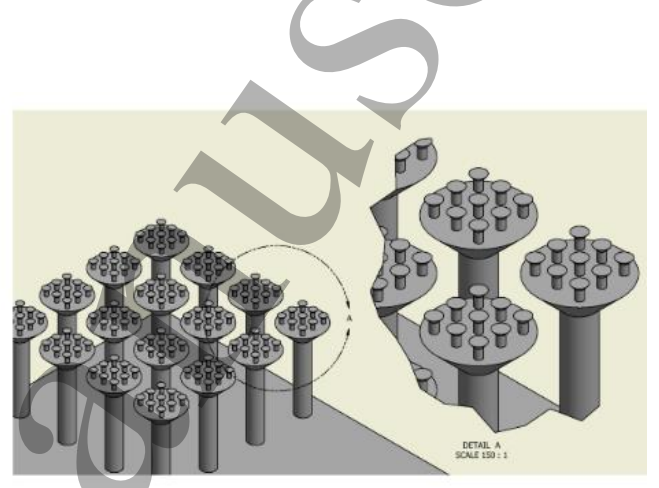

(b)

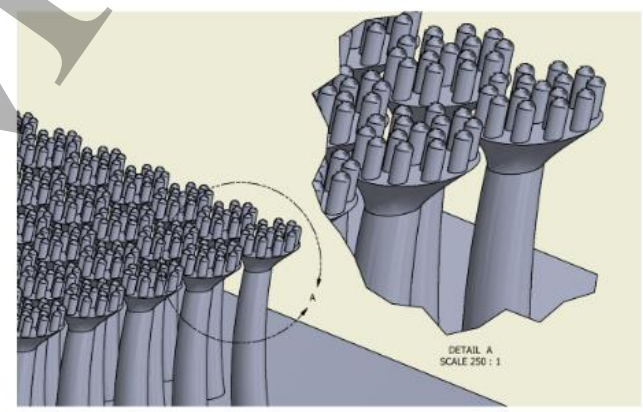

(d)

Fig. 3 Bio-inspired features design (a) top and side views (dimensions in $\mathrm{mm}$ ). Isometric views of (b) D1 (c) D2 (d) D3.

\subsection{Geometrical measurements}

Measurements were conducted by means of an Alicona Infinite Focus 3D microscope that is maintained calibrated by the Metrology Group at the Technical University of Denmark. The measurement procedure consisted in a stratified sampling, where each sample surface was divided in 9 regions, each region subjected to a randomized sampling. Using this approach, the dimensional representativeness is improved reducing error.

Two optical magnifications were applied, 10X for the pillars and 20X for smaller hair structures. Greater attention was placed on the measurement of the smaller hairs as this is where features reach a critically small size and it is more challenging to fabricate the features in this scale. The 
fabrication of bigger structure is straightforward but in this study to push the limit of the AM machine the hair structures are evaluated. Fig. 4 shows the acquisition of first design features. Due to the top light exposure on the features measurement, undercuts were not detected.

A scanning probe image-processing software (SPIP) was employed for the data analytics. Before measurement extraction, each image was levelled and calibrated to minimize measurement errors. Additionally, a scanning electron microscope (SEM) was used for observation of the samples. Due to the non-conductivity of the polymeric material, a layer of carbon (5-10 nm thickness) was deposited onto the samples prior to SEM imaging.

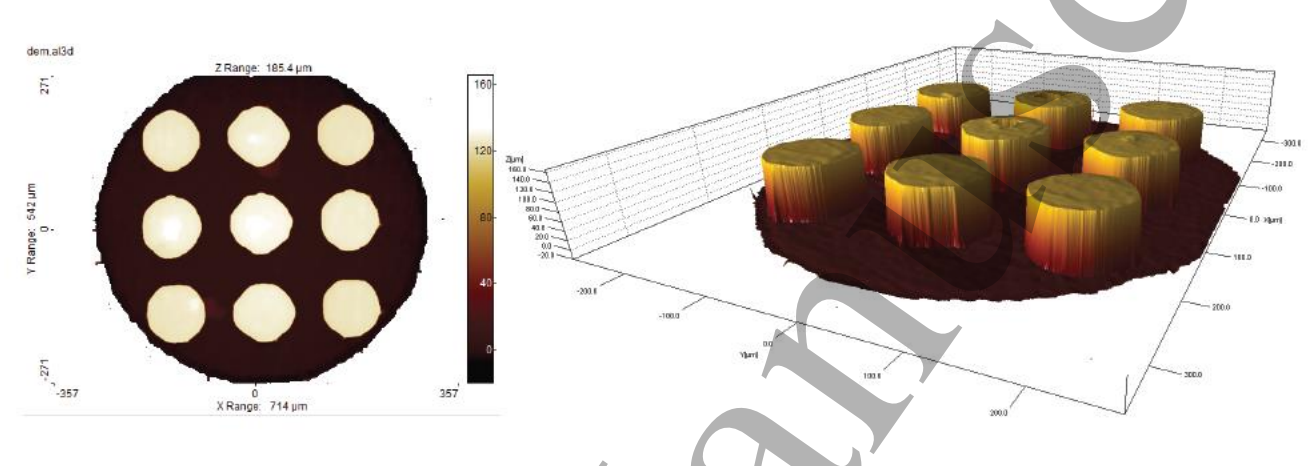

Fig. 4 Acquisition of tips taken by Alicona (20X magnification).

\subsection{Water contact angle (WCA) measurements}

An efficient procedure to test whether the structured surface exhibits the same functionalities, found in the surfaces with multi-hierarchical micro structures a wettability test was conduct [16]. Water contact angle measurements (WCA) are often used to characterize the wettability of a solid surface. Based on how the water drop interacts with a solid surface, the surface can be categorized as hydrophilic, hydrophobic, overhydrophobic and superhydrophobic surface [49] [50], Fig. 5 represents the four mentioned wetting regimes.

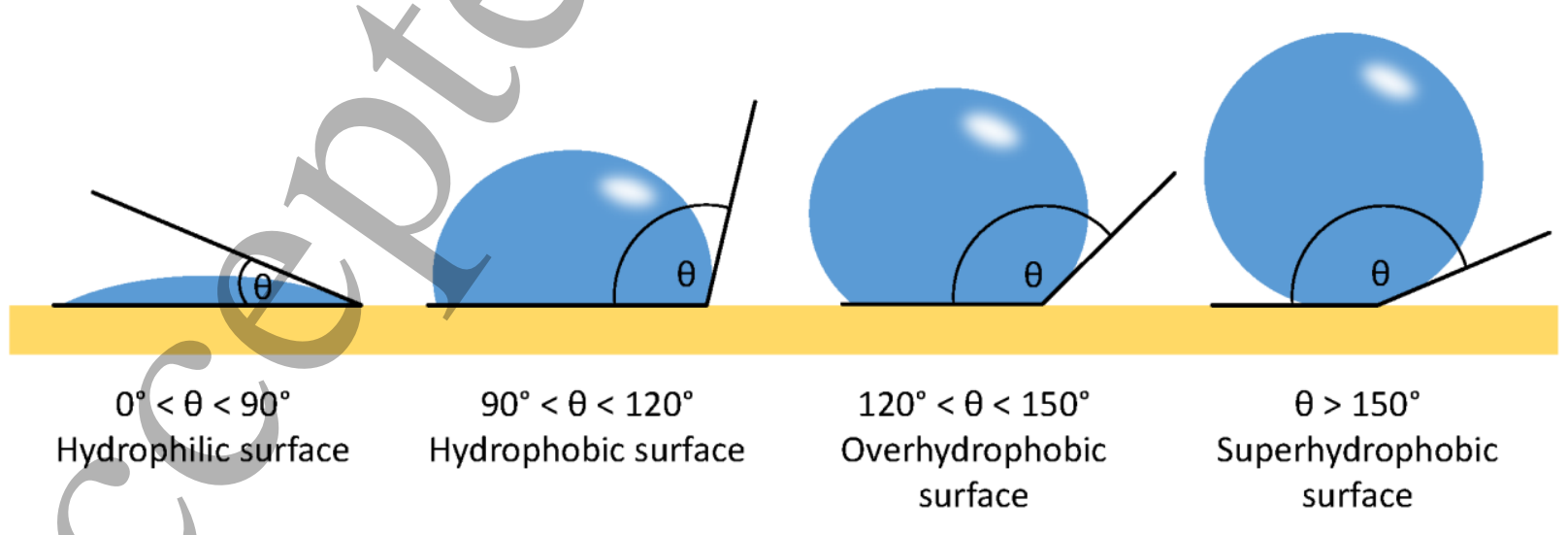

Fig. 5 Wetting regimes for different contact angles. The superhydrophobic state is found to be from $150^{\circ}$. 


\section{Results}

\subsection{Surface samples result}

The experimental parameters reflected that the hairs (small second-level features) diameter were affected by the exposure time (ET) and layer thickness (LT). Fig. 6 shows the measured diameter in a box-plot. Samples with lower LT (D1_1 and D1_3) presented features with clear signs of overexposure; on the other hand, sample D1_2 with lower ET presented underexposed features. Sample D1_4, with higher ET and LT, not only had near-to-nominal $(110 \mu \mathrm{m})$ diameter, it also showed the highest resolution.

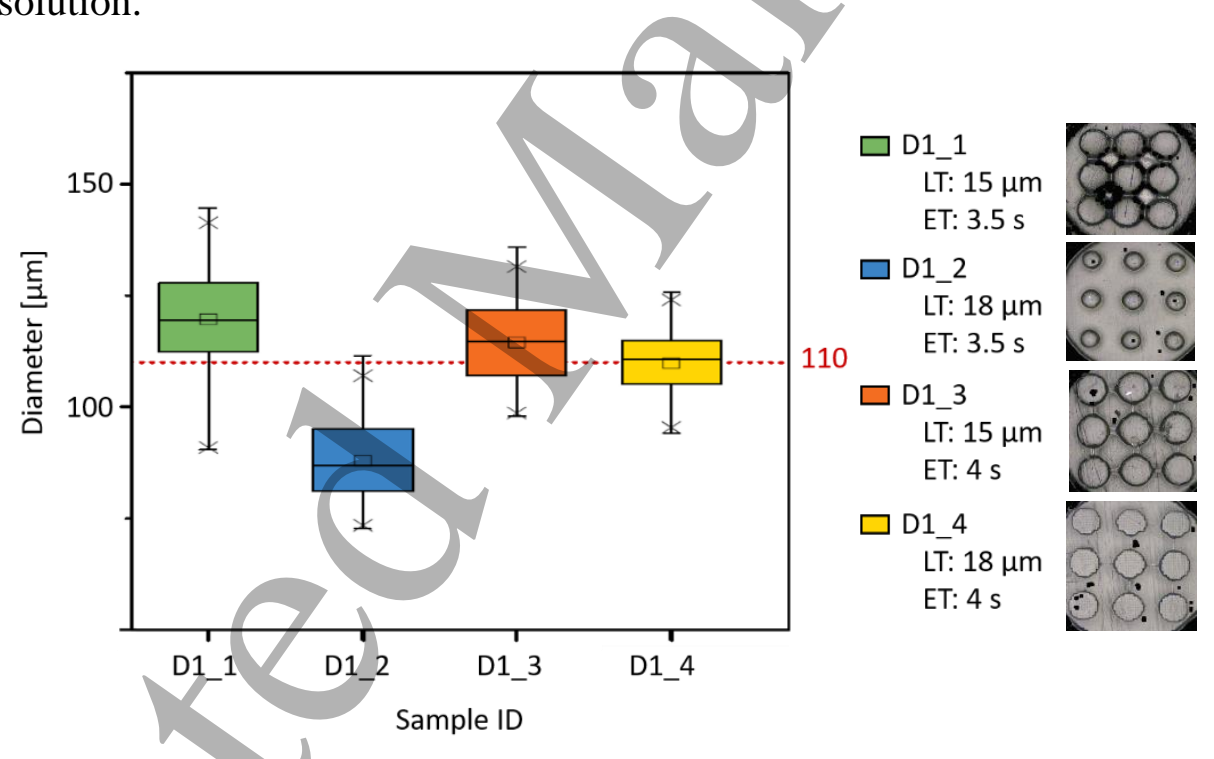

Fig. 6 Box-plot of D1 hair diameters with different process parameters. Sample D1_4 showed values closer to the nominal value $(110 \mu \mathrm{m})$ at a LT $18 \mu \mathrm{m}$ and ET $4 \mathrm{~s}$.

Fig. 7 shows SEM images of sample D1_4. As it can be seen in Fig. 7 (a) left, the array of pillars and hairs were successfully printed with straight and regular features. Fig. 7 (a) right, shows a close-up of one pillar where each of the $18 \mu \mathrm{m}$ layers can be distinguished. The influence of postcleaning protocol greatly affected features separation. Fig.7(c) presents the residual resin between pillars which was not properly dissolved by the solvent used for post-cleaning. Fig. 8 with higher magnification of pillar and hairs shows the clear defined pixels projected from the DMD. 


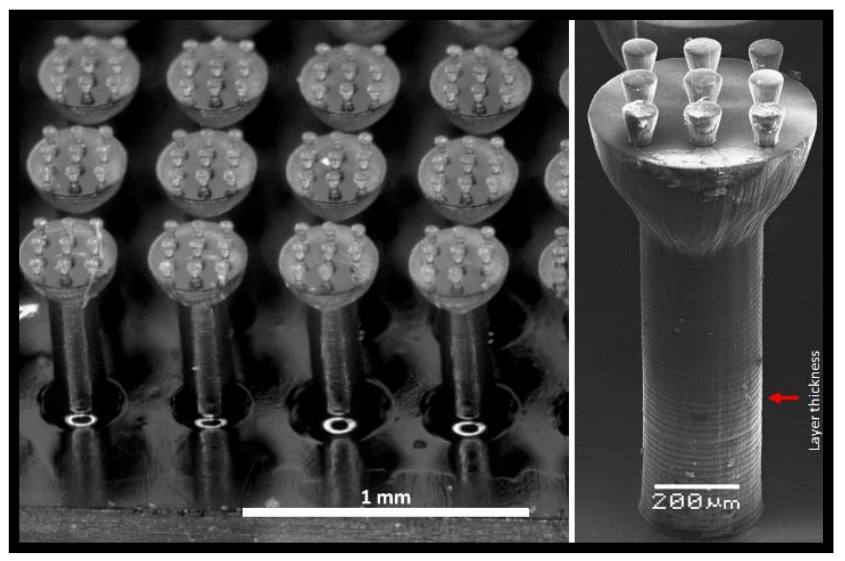

(a)

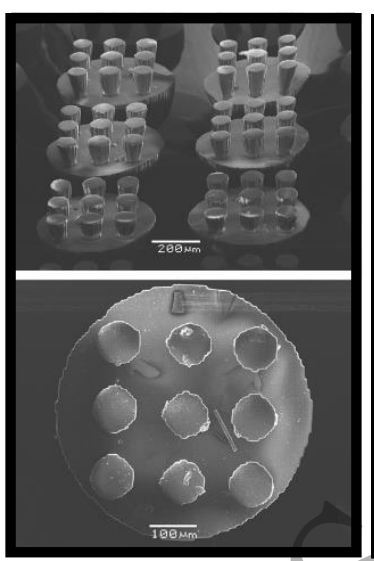

(b)

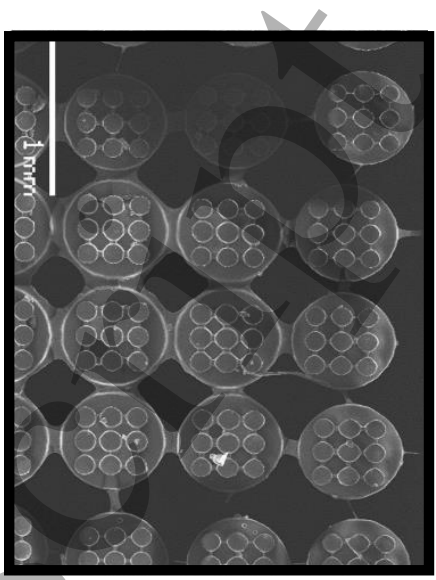

(c)

Fig. 7 SEM images of sample D1_4. (a) Left: Array of micro-pillars, right: Single pillar with visible $18 \mu \mathrm{m}$ layer thickness. (b) Top view of pillars with visible pixel-formation perimeter. (c) Merged pillars due to the inadequate post-cleaning process.

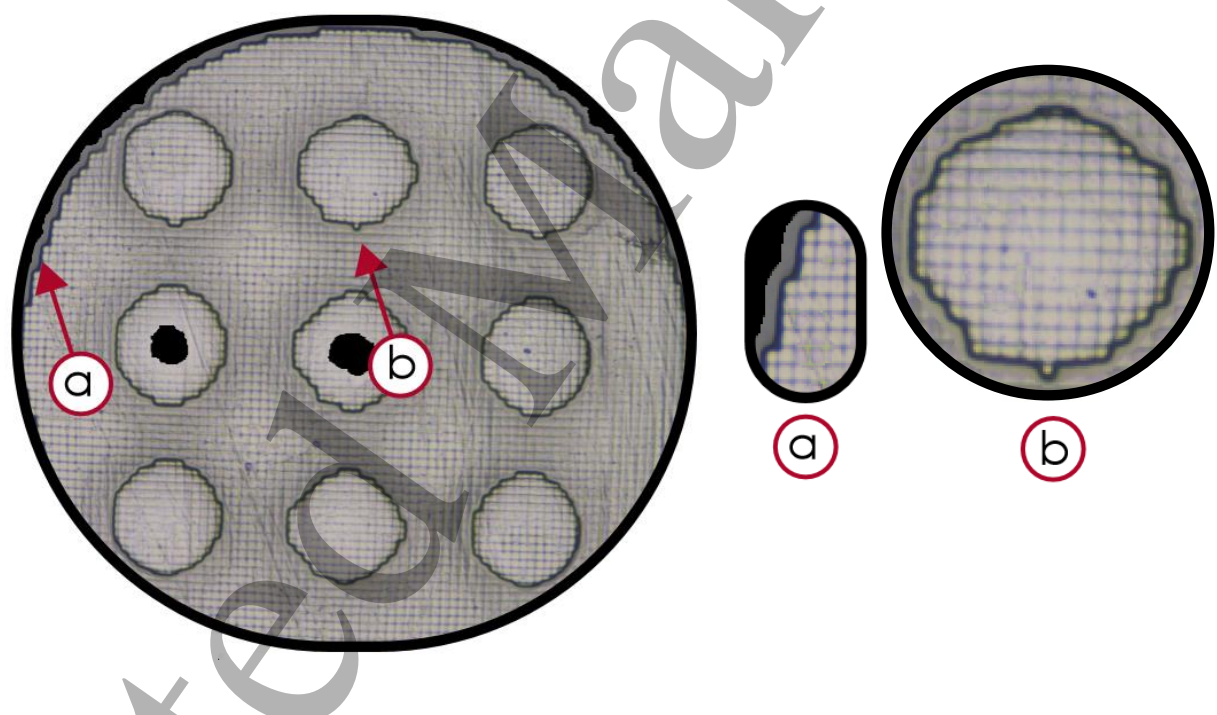

Fig. 8 Top view of a pillar, clear and distinguishable pixels show the high resolution obtained (a) Selected area of pillar edge and (b) Selected area of hair at higher magnification.

Besides the experimental investigations, a DOE analysis was carried out to illustrate the contributions of different parameters on the printing quality. Fig. 9 presents the interaction and the main effect plots on the hair diameter. The layer thickness was observed as an influential factor rather than exposure time. As shown in the main effect plot by increasing the layer thickness to 18 $\mu \mathrm{m}$ smaller diameter was measured, near to the nominal CAD geometry. The determination of the P-value or probability value, of ANOVA with $95 \%$ confidence interval was calculated. The Pvalues are as follows for different factors and combination, the exposure time 0.244 , layer thickness 0.023 and exposure time * layer thickness 0.048 . The P-values less than 0.05 was considered as significant factor and had important influence on the responses. 


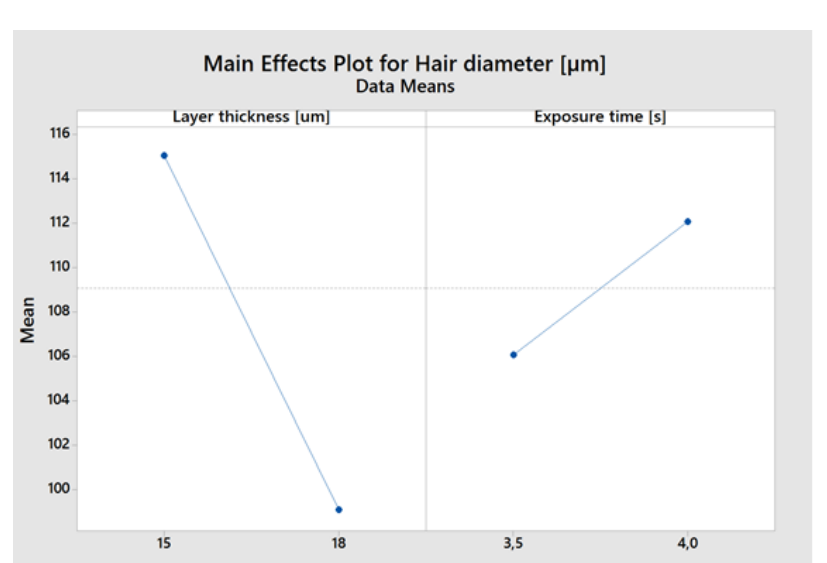

(a)

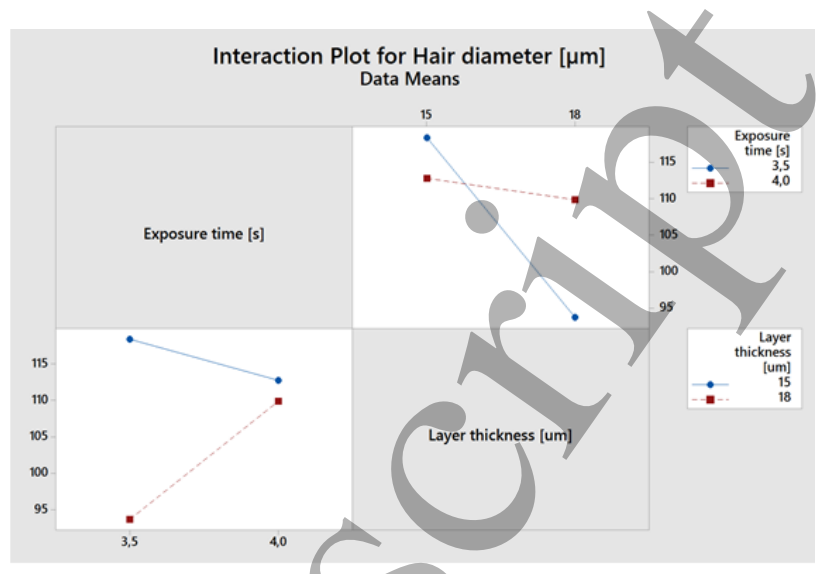

(b)

Fig. 9 (a) Main effects plot of hair diameter (b) Interaction plot of hair diameter

Using the same parameters from sample D1_4, where the best results were achieved, the other designs D2 (Fig. 10) and D3 (Fig. 11) were fabricated. Unlike,D1, where all the micro features were differentiated, the surface quality was diminished. This was traced due to number of reasons such as different sample designs (smaller nominal dimensions and higher feature density), optimization process, and cleaning process. The optimization procedure for printing parameters carried out for the first design with bigger features (the mushroom shape with $100 \mu \mathrm{m}$ diameter and $50 \mu \mathrm{m}$ neck diameter) where D2 had a hair diameter of $50 \mu \mathrm{m}$ with rounded hair-ends, and D3 had hair-ends (also rounded) of $7.6 \mu \mathrm{m}$. In the post processing the same procedure was applied for D2 and D3 however, with smaller features and less distance between them. Consequently, it was more challenging to remove the leftover resin, thus sample D3 had all the hairs completely merged due to excessive density and small size of the micro features. 


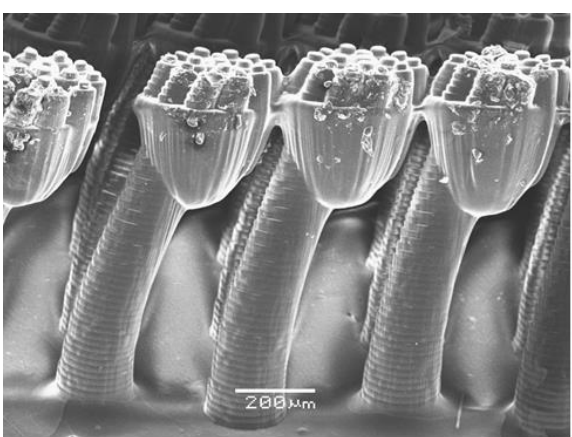

(a)

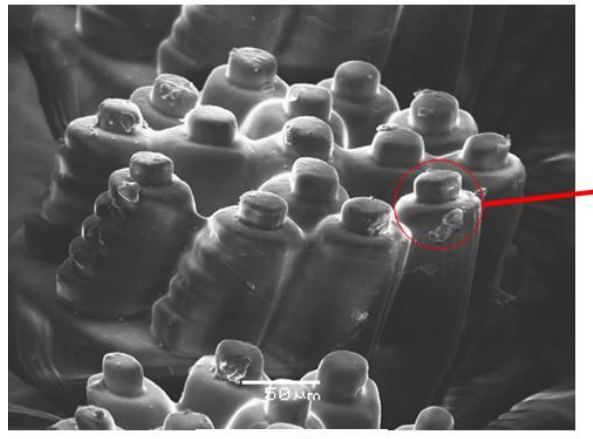

(c)

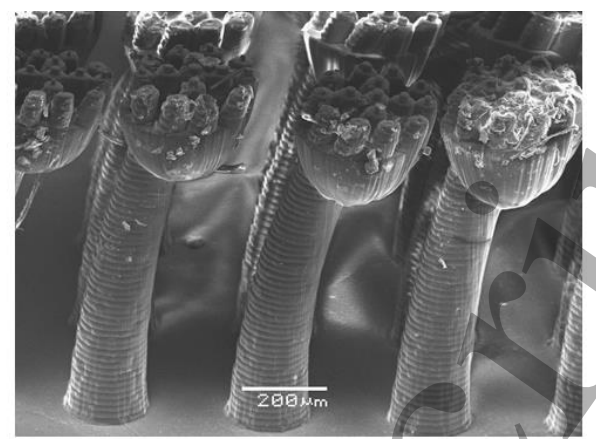

(b)

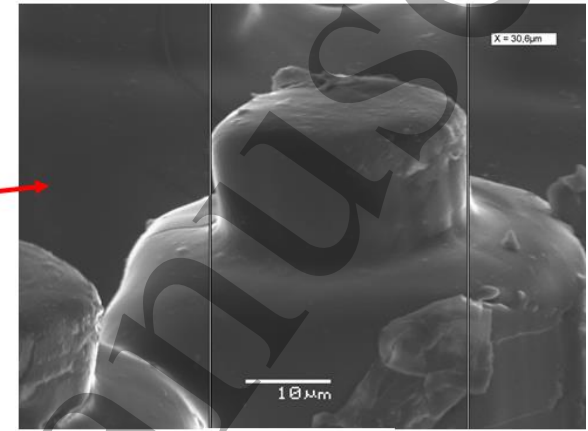

(d)

Fig. 10 D2 SEM images (a) and (b) Side views of the micro features. (c) Top view of one of the hairs. (d) Top view of one tip.

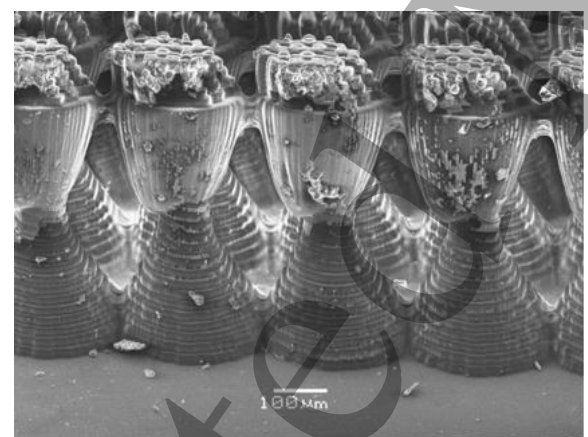

(a)

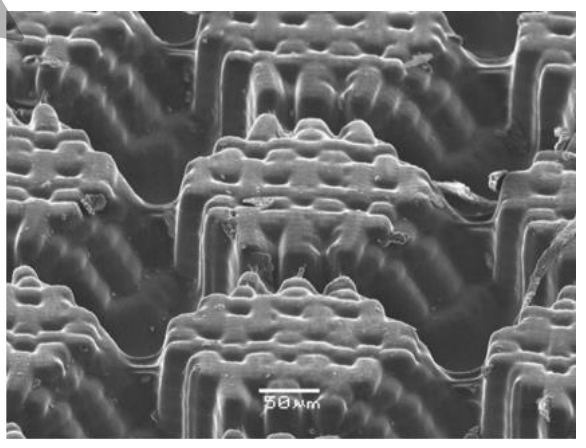

(b)

Fig. 11 D3 SEM images (a) Side view of the micro features. (b) Top view the tips.

\subsection{Wetting Properties}

The WCA of the three different designs can be seen in Fig. 12. All the designs presented a certain degree of hydrophobicity, the results are presented with their final averaged value and standard deviation. D1 (from the literature [36]), is the surface with lowest WCA, $90^{\circ} \pm 2^{\circ}$, which is in the lower limit of hydrophobicity. By increasing the hair density and complexity, higher hydrophobicity was obtained. D2 presents overhydrophobicity with a mean WCA of $124^{\circ} \pm 3^{\circ}$, and D3 resulted a slightly lower hydrophobicity of $116^{\circ} \pm 4^{\circ}$. 


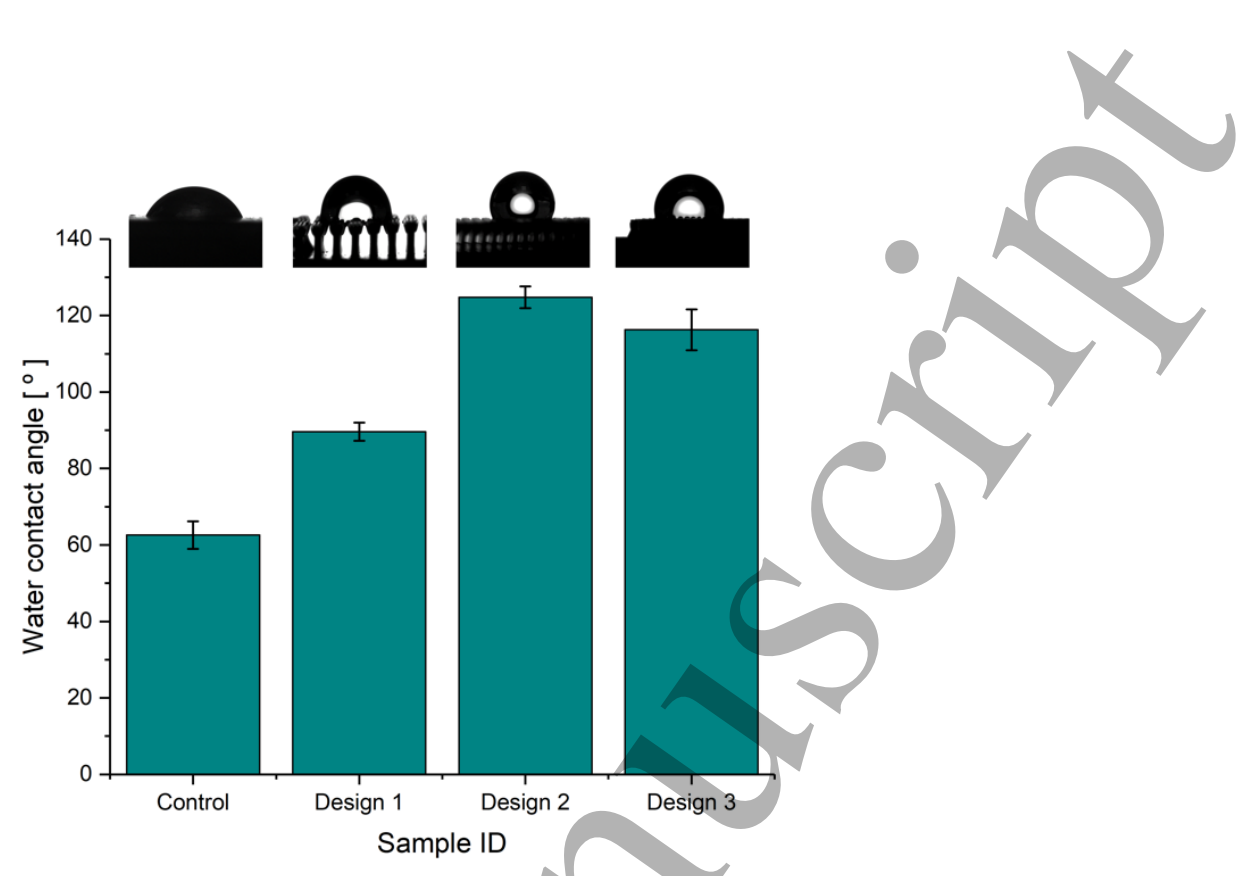

Fig. 12 Water contact angles on gecko-inspired designs. Sámple D2 showed the highest hydrophobicity $\left(124^{\circ} \pm 3^{\circ}\right)$.

These results are in agreement with the Cassie-Baxter equation[50] [52], which defines the contact angle for a liquid drop in a heterogeneous surface where one component is air (gaps between micro features) and the other component is the sample material,

$$
\cos \theta_{r}=f_{s} \cos \theta-\left(1-f_{s}\right)
$$

where $\theta$ and $\theta_{r}$ are the WCA on smooth and texturized surfaces respectively, and $f_{s}$ is the area fraction of the hierarchical surface. According to Cassie-Baxter model, as the area fraction decreases, the WCA is increased. As seen in the SEM images, D2 had features of $30 \mu \mathrm{m}$ (Fig. 10 (d)), in contrast, D1 had a diameter of $100 \mu \mathrm{m}$ (Fig 7 (a)) and D3 had merged features of around $50 \mu \mathrm{m}$ altogether, as seen in Fig. 11 (b). Hence, the results presented a coherent agreement with the theory, where smaller and denser features achieve higher hydrophobicity levels.

\section{Conclusion}

In conclusion, the Tokay gecko (multi-hierarchical surface) has been proven to be directly manufacturable by photopolymer based AM method. This is a simpler and less time consuming process chain than previous methods used for manufacturing of similar surfaces. The samples tests were Tokay gecko-inspired test part with simplified micro designs features. After a process optimization, the samples printed were within a $\pm 9 \mu \mathrm{m}$ tolerance range from the nominal values of the CAD model, this is supported by the measurement of the circular hair features. In addition, a wettability test was carried out revealing high hydrophobicity of the surfaces due to the higher density of the features. The results of this study prove the possibility of 3D printed bio-surfaces which may become commercially viable in the near future. The improvements to the DLP machine, material and removal of error sources, would likely be possible to reach the minimum theoretical feature size, or even sub-pixel resolution by DMD manipulation. Hence, further 
investigation ought to be directed to achieving a better alignment between DLP technology and the small scale printing of complex bio-inspired surfaces.

\section{ACKNOWLEDGEMENT}

The research leading to these results has received funding from the People Programme (Marie Curie Actions) of the European Union's Seventh Framework Programme (FP7/2007-2013) under REA grant agreement No. 609405 (COFUNDPostdocDTU).

\section{References}

[1] J. F. V Vincent, O. A. Bogatyreva, N. R. Bogatyrev, A. Bowyer, and A.-K. Pahl, "Biomimetics: its practice and theory."

[2] A. von Gleich, C. Pade, U. Petschow, and E. Pissarskoi, "Introduction," in Potentials and Trends in Biomimetics, Berlin, Heidelberg: Springer Berlin Heidelberg, 2010, pp. 9-11.

[3] L. De Chiffre, H. Kunzmann, G. N. Peggs, and D. A. Lucca, "Surfaces in Precision Engineering, Microengineering and Nanotechnology," CIRP/Ann. - Manuf. Technol., vol. 52, no. 2, pp. 561-577, 2003.

[4] H. Ko, H. Yi, and H. E. Jeong, "Wall and ceiling climbing quadruped robot with superior water repellency manufactured using 3D printing (UNIclimb)," Int. J. Precis. Eng. Manuf. Technol., vol. 4, no. 3, pp. 273-280, Jul. 2017.

[5] L. R. Palmer, E. Diller, and R. D. Quinn, "Toward gravity-independent climbing using a biologically inspired distributed inward gripping strategy," IEEE/ASME Trans. Mechatronics, vol. 20, no. 2, pp. 631-640, 2015.

[6] E. A. Favret and N. O. Fuentes, Functional properties of bio-inspired surfaces : characterization and technological applications. World Scientific, 2009.

[7] Y. Y. Liu et al., "Artificial lotus leaf structures from assembling carbon nanotubes and their applications in hydrophobic textiles," J. Mater. Chem., vol. 17, no. 11, pp. 10711078, 2007.

[8] D. R. King, M. D. Bartlett, C. A. Gilman, D. J. Irschick, and A. J. Crosby, "Creating GeckoLike Adhesives for 'Real World' Surfaces," Adv. Mater., vol. 26, no. 25, pp. 4345-4351, Jul. 2014.

[9] S. J. Abbott and P. H. Gaskell, "Mass production of bio-inspired structured surfaces," 2007.

[10] A. Malshe, K. Rajurkar, A. Samant, H. N. Hansen, S. Bapat, and W. Jiang, "Bio-inspired functional surfaces for advanced applications," CIRP Ann. - Manuf. Technol., vol. 62, pp. 607-628, 2013.

[11] G. Huber, S. N. Gorb, N. Hosoda, R. Spolenak, and E. Arzt, "Influence of surface roughness on gecko adhesion." 
[12] K. Autumn et al., "Evidence for van der Waals adhesion in gecko setae.," Proc. Natl. Acad. Sci. U. S. A., vol. 99, no. 19, pp. 12252-6, Sep. 2002.

[13] "A comparative analysis of clinging ability among pad-bearing lizards," Biol. J. Linn. Soc., vol. 59, no. 1, pp. 21-35, Sep. 1996.

[14] G. Huber, S. N. Gorb, R. Spolenak, and E. Arzt, "Resolving the nanoscale adhesion of individual gecko spatulae by atomic force microscopy.," Biol. Lett., vol. 1, no. 1, pp. 2-4, Mar. 2005.

[15] R. J. Full et al., "Adhesive force of a single gecko foot-hair," Nature, vol. 405, no. 6787, pp. 681-685, Jun. 2000.

[16] Y. Zhang, S. Qu, X. Cheng, X. Gao, and X. Guo, "Fabrication and Characterization of Gecko-inspired Dry Adhesion, Superhydrophobicity and Wet Self-cleaning Surfaces," J. Bionic Eng., vol. 13, pp. 132-142, 2016.

[17] A. Y. Stark, T. W. Sullivan, and P. H. Niewiarowski, "The effect of surface water and wetting on gecko adhesion," J. Exp. Biol., vol. 215, no. 17, 2012.

[18] K. Autumn, “How Gecko Toes Stick," Am. Sci,, vol. 94, no. 2, p. 124, 2006.

[19] A. Y. Stark, S. Subarajan, D. Jain, P. H. Niewiarowski, and A. Dhinojwala, "Superhydrophobicity of the gecko toe pad: biological optimization versus laboratory maximization," Philos. Trans. R. Soc. London A Math. Phys. Eng. Sci., vol. 374, no. 2073, 2016.

[20] A. Davoudinejad, G. Tosello, and M. Annoni, "Influence of the worn tool affected by builtup edge (BUE) on micro end-milling process performance: A 3D finite element modeling investigation," Int. J. Precis. Eng. Manuf., vol. 18, no. 10, pp. 1321-1332, 2017.

[21] A. Davoudinejad, G. Tosello, P. Parenti, and M. Annoni, "3D Finite Element Simulation of Micro End-Milling by Considering the Effect of Tool Run-Out," Micromachines, vol. 8, 187., 2017.

[22] D. J. Guckenberger, T. E. de Groot, A. M. D. Wan, D. J. Beebe, and E. W. K. Young, "Micromilling: A method for ultra-rapid prototyping of plastic microfluidic devices," Lab Chip, vol. 15, no. 11, pp. 2364-2378, Jun. 2015.

[23] L.-M. Low, S. Seetharaman, K.-Q. He, and M. J. Madou, "Microactuators toward microvalves for responsive controlled drug delivery," Sensors Actuators B Chem., vol. 67, no. 1-2, pp. 149-160, Aug. 2000.

[24] Brodoceanu D, C. T. Bauer, E. Kroner, E. Arzt, and T. Kraus, "Hierarchical bioinspired adhesive surfaces-a review," Bioinspir. Biomim, 2016.

[25] Y. Lvov, J. Shi, and F. Hua, "Nanoassembly for Polymer Electronics," Encycl. Nanosci. Nanotechnol., vol. 6, no. 1, pp. 23-51, 2004.

[26] C. Greiner, E. Arzt, and A. del Campo, "Hierarchical Gecko-Like Adhesives," Adv. Mater., 
vol. 21, no. 4, pp. 479-482, Jan. 2009.

[27] D. Lipomi, R. Martinez, and L. Cademartiri, "Soft Lithographic Approaches to Nanofabrication," Polym. Sci. Compr. Ref., vol. 7, pp. 211-231, 2012.

[28] H. J. Levinson, "Overview of Lithography," in Principles of Lithography, 2nd ed., Bellingham, Washington USA: SPIE-The International Society for Optical Engineéring, 2005.

[29] Y. Xia and G. M. Whitesides, "Soft Lithography," Angew. Chemie Int. Ed., vol. 37, no. 5, pp. 550-575, Mar. 1998.

[30] A. Flores and M. R., "Soft Lithographic Fabrication of Micro Optic and Guided Wave Devices," in Lithography, InTech, 2010.

[31] 52900:2015 ISO/ASTM, “Additive manufacturing -- General principles -- Terminology." Standard, International Organization for Standardization, p. 19, 2015.

[32] M. T. Northen, C. Greiner, E. Arzt, and K. L. Turner, "A Gecko-Inspired Reversible Adhesive," Adv. Mater., vol. 20, no. 20, pp. 3905-3909, Oct. 2008.

[33] M. Röhrig, M. Thiel, M. Worgull, and H. Hölscher, "3D Direct Laser Writing of Nano- and Microstructured Hierarchical Gecko-Mimicking Surfaces," Small, vol. 8, no. 19, pp. 30093015, Oct. 2012.

[34] W. Haske et al., "65 nm feature sizes using visible wavelength 3-D multiphoton lithography," Opt. Express, vol. 15, no. 6, pp. 3426-3436, Mar. 2007.

[35] L. Brigo et al., "3D high-resolution two-photon crosslinked hydrogel structures for biological studies," Acta Biomater., vol. 55, pp. 373-384, Jun. 2017.

[36] M. P. Murphy, S. Kim, and M. Sitti, "Enhanced Adhesion by Gecko-Inspired Hierarchical Fibrillar Adhesives," ACS Appl. Mater. Interfaces, vol. 1, no. 4, pp. 849-855, 2009.

[37] A. Milionis et al., "Water-Repellent Approaches for 3-D Printed Internal Passages," Mater. Manuf. Process., vol. 31, no. 9, pp. 1162-1170, Jul. 2016.

[38] N. Cohen, A. Dotan, H. Dodiuk, and S. Kenig, "Superhydrophobic Coatings and Their Durability," Mater. Manuf. Process., vol. 31, no. 9, pp. 1143-1155, 2016.

[39] J. Feng, M. T. Tuominen, and J. P. Rothstein, "Hierarchical Superhydrophobic Surfaces Fabricated by Dual-Scale Electron-Beam-Lithography with Well-Ordered Secondary Nanostructures," Adv. Funct. Mater., vol. 21, no. 19, pp. 3715-3722, Oct. 2011.

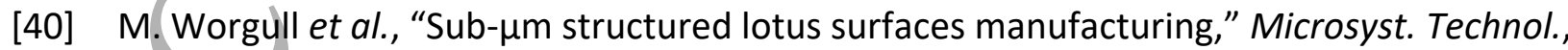
vol. 15, no. 8, pp. 1327-1333, 2009.

[41] M. Méndez Ribó, "3D Printing of Bio-inspired Surfaces," Technical University of Denmark, 2017.

[42] I. Gibson, D. W. Rosen, and B. Stucker, "Photopolymerization Processes," in Additive 
Manufacturing Technologies, Boston, MA: Springer US, 2010, pp. 78-119.

[43] C. Decker, "Photoinitiated crosslinking polymerisation," Prog. Polym. Sci., vol. 21, no. 4, pp. 593-650, Jan. 1996.

[44] ASTM International, F2792-12a - Standard Terminology for Additive Manufacturing Technologies. 2013.

[45] A. R. Jørgensen, "Design and development of an improved direct light processing (DLP) platform for precision additive manufacturing," Technical university of denmark (DTU), 2015.

[46] E. Tyge, J. J. Pallisgaard, M. Lillethorup, N. G. Hjaltalin, M. K. Thompson, and L. H. Clemmensen, "Characterizing Digital Light Processing (DLP) 3D Printed Primitives," in Image Analysis: 19th Scandinavian Conference, SCIA 2015, Copenhagen, Denmark, June 15-17, 2015. Proceedings, R. R. Paulsen and K. S. Pedersen, Eds. Cham: Springer International Publishing, 2015, pp. 302-313.

[47] "LUXBEAM Rapid System." .

[48] A. Davoudinejad, D. B. Pedersen, and G. Tosello, "Evaluation of polymer micro parts produced by additive manufacturing processes by using vat photopolymerization method," in Joint Special Interest Group meeting between euspen and ASPE Dimensional Accuracy and Surface Finish in Additive Manufacturing, 2017.

[49] I. Flores-vivian, V. Hejazi, M. I, Kozhukhova, M. Nosonovsky, and K. Sobolev, "SelfAssembling Particle-Siloxane Coatings for Superhydrophobic Concrete," 2013.

[50] J. Drelich, E. Chibowski, D. D. Meng, and K. Terpilowski, "Hydrophilic and superhydrophilic surfaces and materials," Soft Matter, vol. 7, no. 21, pp. 9804-9828, 2011.

[51] "Contact angle measurements with sessile drops and bubbles," J. Colloid Interface Sci., vol. 145, no. 1, pp. 279-282, Aug. 1991.

[52] A. B. D. Cassie and S. Baxter, "Wettability of porous surfaces," Trans. Faraday Soc., vol. 40, no. 0, p. 546, Jan. 1944. 